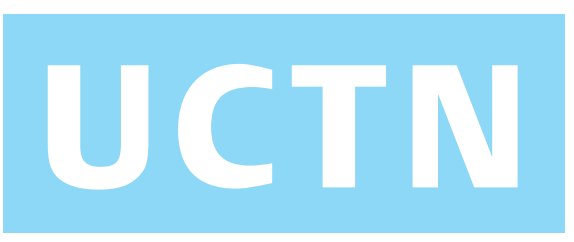

\title{
Autoimmune Polyglandular Syndrome Type II Associated with Jejunal Gastrointestinal Stromal Tumor: Diagnosis by Capsule Endoscopy
}

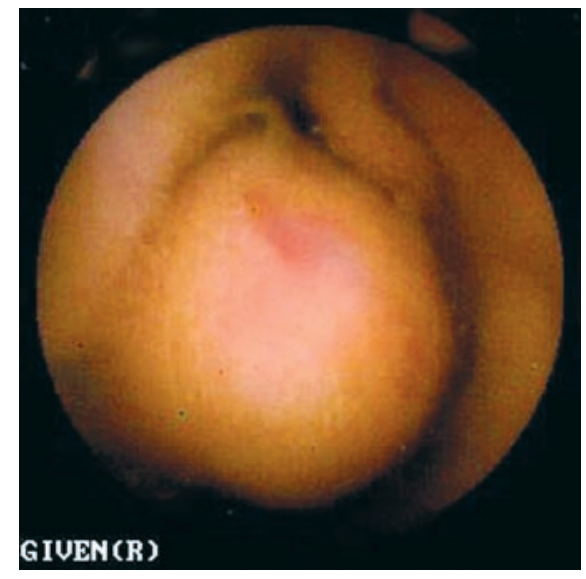

Figure 1 Capsule endoscopy revealed a mass in the proximal jejunum.

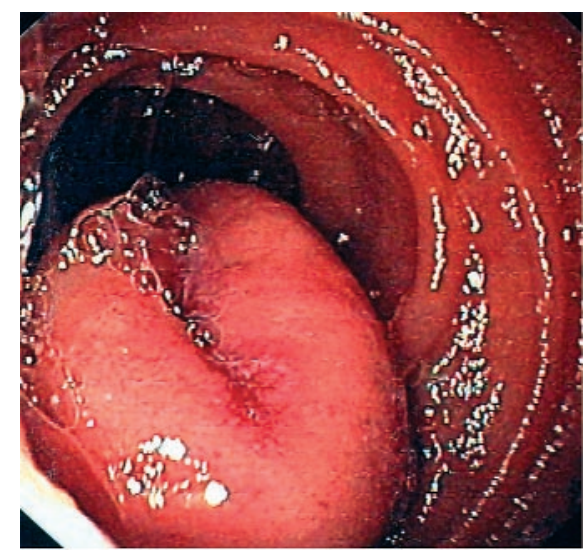

Figure 2 Push enteroscopy confirmed an ovoidal umbilicate protruding jejunal mass.

A 49-year-old woman with autoimmune polyglandular syndrome type II (Addison's disease and hypothyroidism) was referred to our department, as she was suffering from persistent iron-deficiency anemia and had positive results from fecal occult blood test. The history of bleeding was approximately 3 years during which period she had been treated with iron supplementation. Mean $\mathrm{Hb}$ concentration was $8.4 \mathrm{~g} / 100 \mathrm{ml}$ (range 6.1-11.7). Previous diagnostic investigations had included two esophagogastroduodenoscopies, two total colonoscopies, a ${ }^{99} \mathrm{Tc}-\mathrm{la}-$ beled red cells scan, a ${ }^{99} \mathrm{Tc}-$ pertechnetate scan, a small-bowel follow-through in-

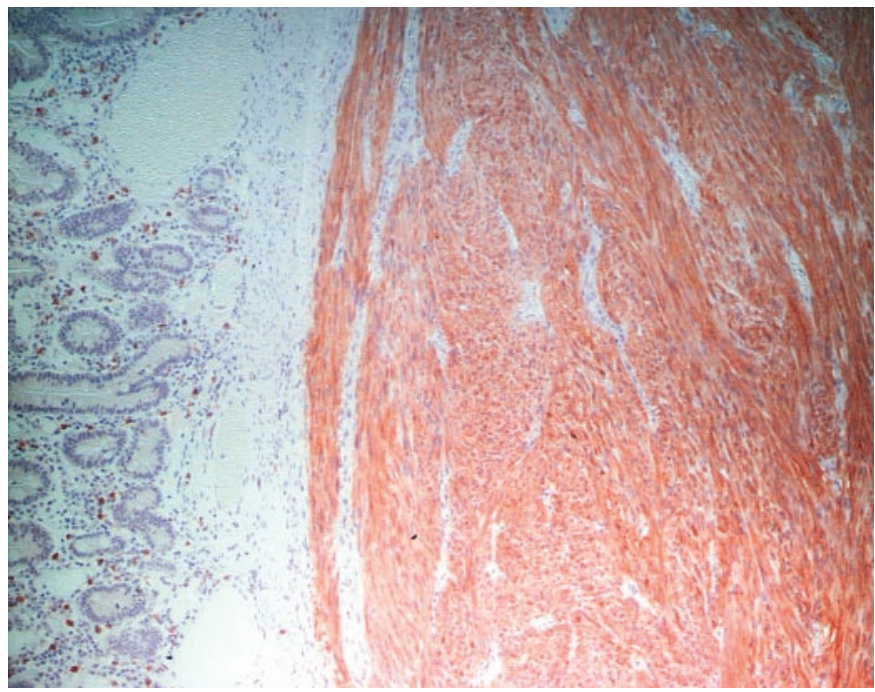

Figure 3 Histopathological examination revealed a highly cellular spindle-cell gastrointestinal stromal tumor (GIST) expressing Kit (CD117 antigen).

vestigation, and a computed tomography (CT) scan. All these tests had failed to identify the source of bleeding.

Capsule endoscopy was performed and identified a small-bowel mass. Rapid $^{\circledR}$ location showed the lesion to be in the upper left midline, and it was estimated to be in the proximal jejunum area (Figure 1). Push enteroscopy was subsequently carried out and confirmed an ovoidal umbilicate protruding mass of the proximal jejunum (size $4 \mathrm{~cm}$ ) (Figure 2). The lesion was resected laparoscopically. The gross specimen of resected small bowel showed that the tumor had a large extraluminal component. No pathological lymph nodes or liver metastases were found. Histopathological investigation demonstrated a highly cellular spindle-cell tumor which turned out to be a gastrointestinal stromal tumor (GIST) expressing Kit (CD117 antigen) (Figure 3).

Tumors of the small bowel comprise $5 \%$ to $7 \%$ of all gastrointestinal tumors. The most important symptom in cases of small-bowel neoplasia is undoubtedly obscure bleeding with secondary iron-deficiency anemia. Indeed, small-bowel tumors are the second most common cause of obscure gastrointestinal bleeding, accounting for $5 \%$ to $10 \%$ of all cases of chronic blood loss. Among patients with obscure gastrointestinal bleeding, smallbowel tumors are the single most common lesion in patients younger than 50 years [1]. The median time to diagnosis for patients with obscure bleeding has been estimated as 2 years [2]. Delays in diagnosis may alter the outcome, and should be minimized whenever possible. Careful utilization of diagnostic examinations may lead to early identification of a potential small-bowel bleeding source and may help improve the diagnostic outcome while decreasing the cost of hospitalization.

Our patient was ultimately diagnosed by means of capsule endoscopy to have a small-bowel tumor and underwent curative surgery. If capsule endoscopy is carried out early in the course of the workup of these patients (i.e. immediately after negative esophagogastroduodenoscopy and colonoscopy), it could shorten considerably the time necessary to reach a diagnosis and allow the early institution of definitive treatment in a significant proportion of patients [3]. 
M. Pennazio', A. Arrigoni', T. Sprujevnik' ${ }^{1}$, A. Bertone', ${ }^{1}$ M. Cavallero', M. Spandre', F. Calvo ${ }^{2}$, M. Mineccia ${ }^{2}$, E. Berardengo ${ }^{3}$, G. Canavese ${ }^{3}$, V. Alvisi ${ }^{4}$

${ }^{1}$ Division of Gastroenterology,

Department of Oncology, S. Giovanni AS Hospital, Turin, Italy

${ }^{2}$ Division of Surgery, Department of Oncology, S. Giovanni A.S. Hospital, Turin, Italy

${ }^{3}$ Division of Surgical Pathology, Department of Oncology, S. Giovanni A.S. Hospital, Turin, Italy

${ }^{4}$ Postgraduate School of Gastroenterology, University of Ferrara, Ferrara, Italy.

\section{References}

${ }^{1}$ Rossini FP, Risio M, Pennazio M. Small bowel tumors and polyposis syndromes. Gastrointest Endosc Clin N Am 1999; 9: $93-114$

2 Zuckerman GR, Prakash C, Askin MP, Lewis BS. AGA technical review on the evaluation and management of occult and obscure gastrointestinal bleeding. Gastroenterology 2000; 118: 201 - 221

${ }^{3}$ Ell C, Remke S, May A, Helou L et al. The first prospective controlled trial comparing wireless capsule endoscopy with push enteroscopy in chronic gastrointestinal bleeding. Endoscopy 2002; 34: 685 - 689
Corresponding Author

\section{Pennazio, M.D.}

Gastroenterology Unit 2

Department of Oncology

S. Giovanni A.S. Hospital

Via Cavour 31

10123 Turin

Italy

Fax: $\quad+39-011-6333979$

E-mail: mpen60@yahoo.com

\section{Highlights from Forthcoming Issues}

State-of-the-Art Review: Diagnostic Laparoscopy

J. L. Parra, K. R. Reddy

The Efficacy of a New Multi-Bending Scope (M-Scope) for Endoscopic Mucosal Resection (EMR)

K. Isshi, H. Tajiri, J. Fujisaki, K. Mochizuki, K. Matsuda, Y. Nakamura, N. Saito, N. Narimiya

Endoscopic Mucosal Resection in the Esophagus Using a New Rigid Device: An Animal Study

A. Radu, P. Grosjean, C. Fontolliet, P. Monnier
Evaluation of Endoscopic Mucosal Resection in Lesions of Laterally Spreading Tumors Located in the Rectum

S. Tamura, K. Nakajo, Y. Yokoyama,

K. Ohkawauchi, T. Yamada, Y. Higashidani,

T. Miyamoto, H. Ueta, S. Onishi

Atypical Endoscopic Features of Rectal Carcinoids

K.-N. Shim, S.-K. Yang, S.-J. Myung, H.-S. Chang, S.-A. Jung, J. W. Choe, Y. J. Lee, J. S. Byeon, J. H. Lee, H.-Y. Jung, W.-S. Hong, J.-H. Kim, Y. I. Min,

J. C. Kim, J.-S. Kim

Endoscopic Suprapapillary Blunt Dissection of the Distal CBD in Cases of Difficult Cannulation: A Pilot Series

K. Hashiba, M. A. D’Assuncao, S. N. Armellini,

R. T. Hassegawa, C. A. Cappellanes, D. Moribe
Study of the Mechanisms of Biliary Stent Occlusion: An Analysis of Occluded and NonOccluded Stents with Emphasis on the Role of Antinucleating Biliary APF

F. Prat, C. Cosson, N. Domingo, O. Chapat, D. Fompeydie, N. Nassar, J. Fritsch, A. D. Choury, G. Pelletier, C. Buffet

A New Self-Expanding Nitinol Stent (JoStent ${ }^{\circledR}$ SelfX) for Palliation of Malignant Biliary Obstruction: A Pilot Study A. May, C. Ell 